\title{
HUBUNGAN UMUR DAN PENGETAHUAN MAHASISWI SEMESTER III DENGAN PEMERIKSAAN PAYUDARA SENDIRI (SADARI) DI AKADEMI KEBIDANAN BUDI MULIA PALEMBANG TAHUN 2018.
}

\author{
Bina Aquari \\ Akademi Kebidanan Budi Mulia Palembang
}

\section{Informasi Artikel :}

Diterima : $\quad$ November 2018

Disetujui : $\quad$ Desember 2018

\section{"Korespondensi Penulis :}

Binaplb2201@gmail.com

\begin{abstract}
A B S T R A K
Penyakit kanker payudara merupakan masalah kesehatan dunia dilihat dari terjadinya peningkatan insiden, prevalensi dan tingkat morbiditasnya. Perlunya dilakukan upaya untuk pencegahan ksnker payudara melalui deteksi dini yang dikenal dengan metode SADARI (Pemeriksaan payudara sendiri). Tujuan penelitian ini untuk mengetahui apakah ada hubungan umur dan pengetahuan dengan pemeriksaan payudara sendiri (SADARI) di Akademi Kebidanan Budi Mulia Palembang Tahun 2018. Rumusan masalah penelitian ini adalah apakah ada hubungan antara umur dan pengetahuan dengan pemeriksaan payudara sendiri (SADARI) di Akbid Budi Mulia Palembang Tahun 2018. Penelitian ini menggunakan survey analitik dengan pendekatan cross sectional yang dilakukan dengan kuesioner. Uji Statistic yang dipakai adalah Uji Chi-Square. Populasi dalam penelitian ini berjumlah 40 orang dan seluruh Populasi dijadikan sampel. Dari hasil analisa univariat responden yang melakukan pemeriksaan payudara sendiri ( SADARI) yaitu sebanyak 23 orang (57,5\%), dan 17 orang $(42,5 \%)$ yang tidak melakukan pemeriksaan sendiri ( SADARI). Responden yang berumur tua sebanyak 33 orang $(82,2 \%)$, sedangkan responden yang berumur muda sebanyak 7 orang $(17,5 \%)$. Responden yang pengetahuan baik sebanyak 16 orang $(40,0 \%)$ dan pengetahuan kurang $24(60,0 \%)$. Hasil analisa statistik dengan menggunakan Uji Chi-Square dengan $\mathrm{df}=1$ ada hubungan yang bermakna umur dengan pemeriksaan payudara diperoleh $p$ value (0.029) lebih kecil dari $(0,05)$ dan ada hubungan yang bermakna pengetahuan dengan pemeriksaan payudara sendiri (SADARI) diperoleh $p$ value $(0,005)$ lebih kecil dari (0,05). Saran untuk mahasiswi Akbid Budi Mulia Palembang hendaknya mahasiswi dapat meningkatkan kesadaran tentang kesehatan untuk dirinya sendiri karena mendeteksi kanker payudara secara dini adalah upaya untuk menjaga kesehatan untuk dirinya sendiri.
\end{abstract}

Kata Kunci : SADARI

\begin{abstract}
Breast cancer is the disease of the health problems of the world as seen from the onset of increased incidence, prevalence and levels of morbiditasnya. The need for prevention efforts ksnker the breasts through the early detection of known methods of AWARE (breast examination alone). The purpose of this research was to determine whether there is a relationship of age and knowledge with breast self examination (REALIZE) the Academy of Midwifery Budi Mulia Palembang Year 2018. The outline of this research issue is whether there is a relationship between age and knowledge with breast self examination (REALIZE) in Akbid Budi Mulia Palembang Year 2018. This research use analytic survey with cross sectional approach is done with a questionnaire. The test Statistic used is the Chi-Square Test. The population in this study amounted to 40 people and the whole Population be used as samples. From the results of the univariate analysis respondents who do breast self examination (REALIZE) that as many as 23 people (57.5\%), and 17 (42.5\%) who did not do its own examination (AWARE). Respondents aged parents as many as 33 people (82.2\%), while respondents aged young as much as 7 people (17.5\%). A good knowledge of the respondent as much as 16 people (40.0\%) and less knowledge 24 (60.0\%). The results of the statistical analysis using Chi-Square Test with $d f=1$ there is a
\end{abstract}


meaningful relationship age with breast examination obtained $p$ value (0.029) smaller than (0.05) and there is a meaningful relationship with the knowledge examination (breast self- REALIZE) obtained p value (0.005) smaller than (0.05). Advice for student Akbid Budi Mulia Palembang Sorority should be able to raise awareness about health for herself for detecting breast cancer early is an effort to maintain health for himself.

\section{PENDAHULUAN ${ }^{*}$}

Di Indonesia, kanker payudara menempati posisi kedua setelah kanker rahim. Fakta lain menunjukkan bahwa sekitar $85 \%$ kaum wanita menemukan benjolan di payudara nya sendiri melalui rabaan (Wibisono, 2009).

Tenaga kesehatan sangat berperan dalam pemeriksaan payudara sendiri (SADARI) yaitu mengadakan pelatihan demi meningkatkan kepedulian kaum wanita un tuk medeteksi lebih dini kanker payudara. Pelatihan sederhana yang dapat dilakukan adalah pemeriksaan payudara klinis (CBE) sehingga dapat membantu kaum wanita (Setianti,2009).

Adapun faktor-faktor yang berhubungan dengan pemeriksaan payudara sendiri atau sadari yaitu usia/umur, riwayat menstruasi (Yustiana, 2013, dan, pengetahuan juga salah satu faktor yang berhubungan dengan pemeriksaan payudara sendiri atau sadari (Dwi Sri, 2008). Pengetahuan merupakan dasar utama tentang pemeriksaan payudara sendiri maka akan mempengaruhi sikap para wanita untuk menyadari pentingnya pemeriksaan payudara sendiri untuk mencegah kanker payudara.

Berdasarkan data dari Medical Record Rumah Sakit Umum Pusat Dr. Mohammad Hoesin Palembang. Jumlah penderita kanker payudara tahun 2011 sebanyak 872 orang, kemudian meningkat $14,7 \%$ menjadi 1000 orang. Kemudian pada tahun 2012 menurun 16,4\% menjadi 846 Orang. Cancer mammae di Rumah Sakit Umum Pusat Dr.Mohammad Hoesin Palembang menduduki peringkat pertama setelah kanker serviks. (RSUP.Dr.Mohammad Hoesin Palembang, 2014)

Berdasarkan identifikasi masalah di atas, karna keterbatasan tenaga, pikiran, biaya dan waktu maka, peneliti hanya meneliti 2 variabel yaitu umur dan pengetahuan sebagai variabel independen dengan pemeriksaan payudara sendiri (SADARI) sebagai variabel dependen pada Mahasiswi Akbid Budi Mulia Palembang Tahun 2018.

Diketahui ada hubungan umur dan pengetahuan secara simultan dengan pemeriksaan payudara sendiri (SADARI) pada mahasiswi Akbid Budi Mulia Palembang Tahun 2018.
Umur memiliki pengaruh terhadap Pemeriksaan payudara sendiri (SADARI), Pemeriksaan dilakukan sebaiknya pada usia 20 tahun karena dapat menghindarkan wanita dari kanker payudara. Kelainan-kelainan pada payudara dapat dideteksi sedini mungkin dengan mengenal payudara sendiri serta melakukan pemeriksaan payudara sendiri (SADARI) sangat bermanfaat bagi para wanita pada usia dewasa awal (Alydapermana, 2012)

Pengetahuan merupakan dasar utama pada pemeriksaan payudara sendiri. Semakin meningkatnya tingkat pengetahuan tentang pemeriksaan payudara sendiri maka akan mempengaruhi sikap para wanita untuk menyadari pentingnya pemeriksaan payudara sendiri untuk mencegah kanker payudara (Dwi sri,2008).

\section{METODE PENELITIAN}

Desain penelitian ini menggunakan metode survey analtik dengan menggunakan pendekatan Cross sectional dimana variabel independen umur, pengetahuan dan prilaku mahasiswi serta variabel dependen pemeriksaan payudara sendiri (SADARI) akan dikumpulkan dalam waktu yang bersamaan. (Notoatmodjo, 2012).

Waktu penelitian dilaksanakan pada Bulan Agustus - September 2018 di Akbid Budi Mulia Palembang.

Populasi dalam penelitian ini adalah jumlah keseluruhan dari objek yang diteliti. Populasi penelitian ini adalah mahasiswi Akbid Budi Mulia Palembang semester III yang berjumlah 40 responden.

Sampel diambil dari jumlah populasi hal ini sesuai dengan teori Arikunto yang mengatakan jika populasi kurang dari 100 orang maka seluruh populasi di jadikan sampel. (Arikunto, 2013) Pengambilan sampel menggunakan metode non random dengan teknik Accidental Sampling yaitu mahasiswi Akbid Budi Mulia Palembang semester III Tahun 2018.

Data dalam penelitian ini menggunakan data primer yaitu data yang didapat dari hasil wawancara langsung dengan responden dengan menggunakan kuesioner.

Analisis data yang digunakan untuk mengetahui hubungan antara variabel dependen (Pemeriksaan Payudara Sendiri /Sadari) dengan variabel independen (Umur dan Pengetahuan), 
Jurnal Kebidanan : Jurnal Medical Science Ilmu Kesehatan Akademi Kebidanan Budi Mulia Palembang Volume.8 No.2, Desember 2018

sehingga dapat diketahu ada hubungan antara umur dan pengetahuan dengan pemeriksaan payudara sendiri (SADARI) pada mahasiswi Akbid Budi Mulia Palembang Tahun 2018. Penelitian ini menggunakan uji statistik "chi square" dengan sistem komputerisasi SPSS.

\section{HASIL DAN PEMBAHASAN}

Pada penelitian ini akseptor $\mathrm{KB}$ aktif berjumlah 40 orang dimana dibagi menjadi dua kategori yaitu Ya apabila mahasiswi melakukan pemeriksaan payudara sendiri atau sadari dan Tidak apabila mahasiswi tidak melakukan pemeriksaan payudaranya sendiri, untuk lebih jelasnya dapat dilihat pada tabel dibawah ini.

Tabel 1.Distribusi Frekuensi Berdasarkan Palembang Tahun 2018

\begin{tabular}{ccc}
\hline Pemeriksaan SADARI & N & $\%$ \\
\hline Ya & 23 & 57,5 \\
Tidak & 17 & 42,5 \\
\hline
\end{tabular}

Dari tabel 1di atas, dapat diketahui bahwa dari 40 responden, Mahasiswi yang melakukan pemeriksaan payudara sendiri yaitu sebanyak 23 responden $(57,5 \%)$ dan yang tidak melakukan pemeriksaan payudara sendiri yaitu sebanyak 17 responden $(42,5 \%)$.

Pada penelitian ini umur responden penelitian dibagi menjadi dua katagori yaitu Tua dan Muda. Untuk lebih jelasnya dapat dilihat pada tabel berikut

Tabel 2. Distribusi Frekuensi Berdasarkan Umur Responden pada Mahasiswi Akbid Budi Mulia Palembang Tahun 2018

\begin{tabular}{lll}
\hline Umur & $\mathbf{N}$ & $\%$ \\
\hline Tua & 33 & 82,5 \\
Muda & 7 & 17,5 \\
\hline
\end{tabular}

Berdasarkan Tabel 2 dapat dilihat dari 40 responden, akseptor yang umur tua 33 orang $(82,5 \%)$ dan akseptor yang umur muda sebesar 7 orang $(17,5 \%)$.

Pada analisis bivariat untuk lebih jelas dapat dilihat pada tabel dibawah ini :

Tabel 3.Hubungan Umur Mahasiswi SMT III dengan Pemeriksaan Payudara sendiri atau sadari di DIII Kebidanan Akbid Budi Mulia Palembang Tahun 2018

\begin{tabular}{|c|c|c|c|c|c|c|c|}
\hline \multirow{3}{*}{ Umur } & \multicolumn{4}{|c|}{ Pemeriksaan Sadari } & \multirow{2}{*}{\multicolumn{2}{|c|}{ Jumlah }} & \multirow{3}{*}{$\rho_{\text {lue }}^{\rho V a}$} \\
\hline & \multicolumn{2}{|c|}{$\mathbf{Y a}$} & \multicolumn{2}{|c|}{ Tidak } & & & \\
\hline & $\mathbf{n}$ & $\%$ & $\mathbf{n}$ & $\%$ & $\mathbf{N}$ & $\%$ & \\
\hline Tua & 22 & 66,7 & 11 & 33,3 & 33 & 100 & 0,029 \\
\hline Muda & 1 & 14,3 & 6 & 85,7 & 7 & 100 & \\
\hline Total & 23 & & 17 & & 40 & & \\
\hline
\end{tabular}

Berdasarkan Tabel 3 Dari hasil uji statistik Chi-Square, didapat nilai $P$ Value sebesar $0,029 \leq \alpha$ 0,05 artinya ada hubungan yang bermakna umur dengan pemeriksaan sadari pada mahasiswi Akbid Budi Mulia Palembang Semester III Tahun 2018.

Hasil penelitian ini sesuai dengan penelitian Penelitian ini sesuai dengan penelitan Rasidji (2010) karena pemasyarakatan kegiatan SADARI bagi semua wanita dimulai sejak usia subur,sebanyak $85 \%$ wanita usia subur melakukan pemeriksaan payudara sendiri atau sadari karena banyak wanita merasa ada kelainan di payudaranya.

Tabel 4. Hubungan Pengetahuan Mahasiswa Semester III dengan Pemeriksaan Sadari di Akbid Budi Mulia Palembang Tahun 2018. Pemeriksaan Sadari

\begin{tabular}{|c|c|c|c|c|c|c|c|}
\hline \multirow[t]{2}{*}{ Umur } & \multicolumn{2}{|c|}{ Ya } & \multicolumn{2}{|c|}{ Tidak } & \multicolumn{2}{|c|}{ Jumlah } & \multirow{2}{*}{$\begin{array}{c}\rho \mathrm{Val} \\
\text { ue }\end{array}$} \\
\hline & $\mathbf{n}$ & $\%$ & $\mathbf{n}$ & $\%$ & $\mathbf{N}$ & $\%$ & \\
\hline Baik & 14 & 87,7 & 2 & 12,5 & 16 & 100 & \\
\hline Kurang & 9 & 37,5 & 15 & 62,5 & 24 & 100 & \\
\hline Total & 23 & & 17 & & 40 & & \\
\hline
\end{tabular}

Berdasarkan Tabel 4 dilihat bahwa Hasil analisa di atas analisis bivariat dengan uji ChiSquare diperoleh $P$ Value sebesar $0,005 \leq \alpha 0,05$ berarti ada hubungan yang bermakna pengetahuan mahasiswi semester III dengan pemeriksaan sadari di Akbid Budi Mulia Palembang terbukti secara statistik.

Hasil penelitian ini sesuai dengan penetitian Berdasarkan hasil penelitian Dwiakhid Martyani (2008) di kelurahan Warungboto kecamatan Umbulharjo D.I Yogyakarta didapatkan hasil pengetahuan baik $43 \%$ sedangkan pengetahuan kurang baik $57 \%$ terhadap pemeriksaan payudara sendiri atau sadari. 
Jurnal Kebidanan : Jurnal Medical Science Ilmu Kesehatan Akademi Kebidanan Budi Mulia Palembang Volume.8 No.2, Desember 2018

\section{KESIMPULAN}

Ada hubungan umur dan pengetahuan mahsiswi secara simultan dengan pemeriksaan payudara sendiri (SADARI) di Akbid Budi Mulia Palembang.

\section{SARAN}

Hendaknya mahasiswi dapat meningkatkan kesadaran tentang kesehatan untuk dirinya sendiri karena mendeteksi kanker payudara secara dini adalah upaya untuk menjaga kesehatan untuk dirinya sendiri

\section{DAFTAR PUSTAKA}

Arikunto, Suharsimi. 2013. Prosedur Penelitian. Jakarta : Rineka Cipta

Astutik., R. Y. Payudara dan Laktasi. Jakarta: Salemba Medika

Depkes RI, 2008. Pencegahan Kanker Leher Rahim dan Kanker Payudara. Jakarta. Diakses dari : hhtp://www.depkes.go.id

Handayani Sri Dwi. 2008. Hubungan Antara Tingkat dan Sikap dengan Perilaku Para Wanita Dewasa Awal Dalam Melakukan Pemeriksaan Payudara Sendiri di Kelurahan Kalangan Kecamatan Pedan Klaten. Jakarta : PSIK FK UNDIP

Luwia, M. 2003. Problematika dan Keperawatan Payudara. Cetakan I. Jakarta: Kawan Pustaka

Medical Record Rumah Sakit Umum Pusat Dr. Mohammad Hoesin Palembang 2014

Noto Atmodjo, soekidjo. 2010. Metodelogi Penelitian Kesehatan. Jakarta : Reneca Citra.

Olfah, Yustiana. 2013. Kanker Payudara dan SADARI. Jakarta : Nuha Medika.

Pustaka S, Rasjidi I. 2009. Epidemiologi Kanker Serviks. Indonesion Journal of Cancer JuliSeptember. 3 rd edition. Pp 103-8

Setiati, Eni. 2009. Waspadai 4 Kanker Ganas Pembunuh Wanita ; Kanker Rahim, Kanker Indung Telur, Kanker Leher rahim, Kanker Payudara. Edisi 1, Penerbit Andi : Jakarta.
Wibisono, Nancy. 2009. Melawan Kanker Payudara. Jakarta : Restu Agung

Yohanes. 2008. Kanker Ancaman Negara Berkembang. Diperoleh dari : http://www.kanker.com.

Setya Arum, Dyah Noviawati. 2009. Panduan Lengkap Pelayanan KB Terkini. Yogyakarta : Nuha Medika.

Siti Mulyani, Nina. 2013. Keluarga Berencana dan Alat Kontrasepsi. Yogyakarta : Nuha Medika.

Sulistyawati, Ari. 2011. Pelayanan Keluarga Berencana. Jakarta : Salemba Medika.

Anugrah Nilasari, Tika. 2013. Konsep Dasar KB. http://www.Konsep-dasarKB.com/artikel/detik/detail :

BKKBN. 2013. Ringkasan Laporan Hasil Pelayanan Kontrasepsi Maret Tahun 2013.

http://bkkbn.co.id/laporan.pelayanan.kontr asepsi

Dwi Haryani, Dewi.2010. Pengaruh Frekuensi Kontrasepsi Suntik DMPA Terhadap . Kenaikan Berat Badan Pada Akseptor Kontrasepsi Su 103ntik DMPA. Jurnal Ilmiah Kebidanan : Poltekes Semarang. http://www.Jurnal.kesehatan.com

Dinkes Kota Palembang. 2012. Profil Kesehatan Kota Palembang Tahun 2012. http://dinkes.palembang.go.id/tampung/do kumen/dokumen-87-120.pdf.

2012. BKKBN Sumsel Targetkan 405.920 Peserta $K B$. http://www.Sripoku.com.Palembang.

Januani Anggia, Riyanti. 2012. Hubungan Jenis dan Lama Pemakaian Komtrasepsi Hormonal dengan Gangguan Menstruasi di BPS Wolita M.J Sawong Kota Surabaya : Universitas Airlangga http://www.Jurnal.kesehatan.com

Kompas. 2008. KB Suntik Paling Dingemari IbuIbu. http.//nasional.kompas.com/read/2008/05/ 
30/20114988.KB.suntik.paling.digemari.ib u.ibu.

Ny Sukmasari, Radian. 2013. Pil dan Suntik Kontrasepsi Terfavorit di Indonesia. http://www.kontasepsi.tervaforit.com/detik Health.

Suparyanto. 2010. Pengaruh KB Suntik Terhadap Perubahan Berat Badan.

Yusnita Saleh, Mawar. 2012. Pengaruh KB Hormonal dan Non Hormonal Terhadap Berat Badan Akseptor di Puskesmas Kebayakan Kec.Kebayakan Kabupaten Acah Tengah Tahun 2012. Jurnal Kesehatan Masyarakat.Stikes Budiyah. http://www.Jurnal.kesehatan.com 
